\title{
Impact of Using Roundhouse Diagram and Discrepancy Strategy to Improve Reflective Thinking Skills to Acquire Scientific Concepts by Primary Third Grade Students in Jordan
}

\author{
Tahani Alebous ${ }^{1}$ \\ ${ }^{1}$ World Islamic Science \& Education University, Jordan \\ Correspondence: Tahani Alebous, World Islamic Science \& Education University, Jordan. E-mail: \\ tahaniabous@yahoo.com
}

Received: November 10, 2018

Accepted: January 18, 2019

Online Published: April 30, 2019

doi:10.5539/mas.v13n5p105

URL: https://doi.org/10.5539/mas.v13n5p105

\begin{abstract}
The study has shown statistically significant effect at the level $(\alpha=0.05)$, for both discrepancy and roundhouse strategies, in improving the thinking skills and acquiring the scientific concepts. In comparison to the traditional way, roundhouse strategy has surpassed the discrepancy strategy in improving reflective thinking skills and scientific concepts for primary third grade students. Therefore, the study recommended the adoption of discrepancy and roundhouse strategies to teach science and including it in the teachers' training courses.
\end{abstract}

Keywords: roundhouse strategy, discrepancy strategy, reflective thinking skills, scientific concepts

\section{Introduction}

Science is one of the major courses in any education system. Internationally, the students' results in science competitive tests measure their levels in different types of thinking. It emphasizes the importance of science material and highlights the role of science teacher in improving the students' abilities and skills by adopting modern teaching strategies and techniques. It also contributes towards enhancement of student's performance and mental abilities, which allows students to apply their learnings in their practical life. This tends to increase their engagement in society (Kuhn \& Dean, 2004).

Scientific educators confirm that one of the major goals of teaching science is to teach students how to think not to memorize. Reflective thinking is one of the types of thinking that allows an individual to plan and assess procedures and steps to take the right decision. Reflective thinking depends on the way of facing problems and the variability of phenomena and incidents. The person who thinks contemplatively is able to recognize relationships, make summaries, use knowledge to support viewpoints, analyze introductions, and search and review alternatives. In addition, reflective thinking includes a variety of skills and elements. Most importantly, perceiving and concluding, discovering mistakes, proposing suggestive solutions, assessing and following logical relationships, and drawing conclusions.

The idea of Constructivism came from the background knowledge. Many strategies have emerged from this philosophy, for instance; the contradictory event. This strategy can be considered effective when the child encounters an event that contradicts with his comprehension and perception. It results from the interference of what is happening and what is expected to happen (Friedl, 1995). The student needs sufficient information which can be gained by noticing, comparing, using tools and equipment from the science lab to solve this contradiction. However, this information cannot solve discrepancy unless they become clear and meaningful. Moreover, this strategy is based on Piaget's theory of Cognitive Development.

The students' recognition of the scientific concepts and their reflective thinking skills will definitely contribute to improve their achievements in the field education. This requires the adoption of new strategies to make learning meaningful. The students are facing difficulties in understanding the scientific concepts. Moreover, The National Center for Human Resources Development in Jordan has revealed a report about the levels of students' performance at Trends in International Mathematics and Science (TIMSS) based on the available pedagogical materials and curriculum. According to some studies, Jordanian students in general have low thinking skills and performance in science (Al-Harahsheh, 2012; Al Shaar, Khattab, Alkaied \& Manna, 2015). Using modern strategies to teach science is crucial; however, it also makes learning meaningful. For instance; the roundhouse 
strategy and discrepancy strategy are based on the constructivist theory. Therefore, this study shows the impact of roundhouse strategy and discrepancy strategy in improving reflective thinking and the acquisition of scientific concepts by primary third grade students in Jordan. The study attempted to test the following Null Hypothesis:

1. The P-value $(\alpha=0.05)$ shows that there were no statistical differences between primary third grade students in acquiring scientific concepts due to the teaching strategy (roundhouse strategy, discrepancy strategy, and the traditional way).

2. The P-value $(\alpha=0.05)$ show that there were no statistical differences between primary third grade students in the reflective thinking skills due to the teaching strategy (roundhouse strategy, discrepancy strategy, and the traditional way).

The study has helped in noticing some difficulties that encounter teachers with primary stages to acquire scientific concepts and reflective thinking skills. Based on the above, there was a deep need for using modern strategies in teaching that can improve students' scientific concepts and thinking effectively. Moreover, they can be used in practical life, for instance; roundhouse strategy and discrepancy strategy. Giving indicators for the science curriculum developers in Jordan define the efficiency of these strategies as it adopted recent curricula for teaching.

\section{Literature Review}

School curriculums aim to prepare citizens for dealing with different new technologies by imparting the teachers with skills of scientific thinking along with its different processes and stages. Many educators have practiced reflective thinking to develop their careers by revising their methods of teaching, discovering strengths and weaknesses, and improving them. Contemporary educators like Schoon, Pollard, Korthagen, Henderson and Font are also concerned with this type of thinking; as reflection builds the learner's conscious about his attitudes, emotions, and beliefs. Reflective thinking can be practiced depending on many strategies and methods of collecting data (Redmond, 2017).

Reed and Canning (Reed \& Canning, 2010) believed that reflective thinking is a status of doubt and hesitation, a challenge that triggers thinking, searching, questioning, finding ways to solve this doubt, and reaching a level of stability and clarity. As for Lyons (Lyons, 2010) reflective thinking requires processing more than issue according to significance, give order for discrepancies, and compare between them. In addition, it gives an opportunity to review, explain, and elaborate the main ideas and goals of the subject. Moreover, reflective thinking can develop accuracy and foresight of a person.

Building and developing learners' scientific concepts is one of the main goals of teaching science. It serves as a way for understanding science and scientific knowledge and the transfer of knowledge using educational methods and strategies that focuses on learners despite their level to guarantee memorizing of the scientific concepts (Martin, Sexton, Franklin, Gerlovich \& McElroy, 2009). Fisher et al. (2000) defined the scientific concept as mapping things, incidents, and properties. It could be defined as the mental perceptions and procedures of scientific phenomena and incidents, which have mutual features and properties that can have the same category. This should be a way of encouraging learner to discover new information also interpret the scientific phenomena correctly.

Teachers are responsible for choosing the teaching strategies, which will help learners to link and comprehend these concepts in a broader sense (Ross \& Wilson, 2012). Malak Al-Saleem (2004) conducted a study to recognize the efficiency of reflective learning in developing the chemical concepts, reflective thinking, and self-learning by high school girls at Al-Riyadh city. Moreover, Quasi-experiment method has been used to test the study depending on chemical concepts test, reflective thinking scale, and self-regulation scale. The study has shown that there were some statistical differences between in the averages of chemical concepts and the reflective thinking samples.

Al-Qatrawi (2010) discussed the impact of strategy in developing science processes and the skills of reflective thinking of primary eighth grade students. The study used the Quasi-experiment method to measure the impact of this strategy on a purposive sample consisted of 64 students. In addition, it was used for science processes and the reflective thinking scale. Statistically, results were in favor of science processes test and the reflective thinking scale samples. Phan (2008) aimed to show the possible effects of classroom environment on performance and reflective also the impact of performance and reflective thinking on the academic achievement. For this purpose, the study tools were applied on sample consisted of 298 students (male and female) chosen from four schools in Sydney, Australia. Results have shown an impact of classroom environment on academic achievement (achievement, proficiency) and the scales of reflective thinking. Moreover, comprehension had the highest average, then came critical thinking, and the average of regular performance was in the last place. Furthermore, there were no statistical differences in the averages of reflective thinking according to gender. There were also direct and indirect effects of classroom environment on reflective thinking practices. 
The study conducted by Westbrook and Rogers (1991) showed how the Learning Cycle motivates the learners' reflective thinking, improves comprehension, and facilitates the scientific investigation. A random sample was chosen from the ninth-grade primary students who studied physics in four classes. Two testing groups learned about simple machines using three methods of learning; while, the standard group depended on Lawson Test, i.e. the traditional way. A pre and post testing was performed on both groups. The results showed that the testing groups have achieved a better improvement than the standard group each time they practice reflective thinking or make a scientific investigation. Kwon et al. (2000) investigated the impact of the discrepancy strategy on the conceptual development of the concepts related to electricity and mechanism in physics. The results showed an apparent impact of the reflective theory on the development of scientific concepts. Moreover, the post-tests results were in favor of the control group.

Barbosa et al. (2011) examined the impact of discrepancy strategy in developing the physical concepts and the values of science of engineering college students. Results have shown an obvious effect for the discrepancy strategy on developing the scientific concepts using meaningful learning. Al-Mazrou (2005) discovered the efficiency of the roundhouse strategy in developing the metacognitive skills and achievement of high school girls in Riyadh, Saudi Arabia. The study sample consisted of 67 students from two classes whom were chosen randomly. The experimental group was taught using roundhouse strategy; while, the control group was taught using the traditional way. The research tools were the scale of the metacognition skills, the academic achievement scale, and the cross shapes test. Results have shown the efficiency of roundhouse strategy in developing the skills of metacognition and the academic achievement of the experimental group. Moreover, results have also shown that the roundhouse strategy did not affect the development of metacognition skills and the academic achievement.

\section{Methodology}

The study has followed the quasi experimental strategy that is appropriate to discuss the problem.

\subsection{Study Population}

The study consisted of 60 female students, who were chosen randomly from three classes (two experimental groups and one control group). The experimental group (class A) consisted of 20 students, who were taught the curriculum of Substance, Power, and Machines using the discrepancy strategy. The curriculum of primary third grade Science book was organized according to the teacher guide. As for the second experimental group (class B) consisting of 19 students were taught the same curriculum using roundhouse strategy, which was organized according to the teacher guide. While, the control group (class C) consisted of 21 students were taught using the traditional way of teaching; according to the teacher guide.

\subsection{Study Instruments}

The study has used two tools to achieve the aim of the study;

- Reflective thinking test - it measures the level of reflective thinking of the study sample in the study units (Matter, Power, and Machines).

- Scientific concepts test - it measures the level of perception of the scientific concepts for primary third grade students. These tools are based on the following steps:

\subsubsection{Reflective Thinking Test}

A test was created to measure reflection and observation, identification of errors, ability to provide convincing explanations, ability to arrive at conclusions, and ability to set suggestive solutions by primary third grade students in science material (Matter, Power and Machines). Knowledge of the pedagogy related to the study, especially previous studies created similar tests for the reflective thinking.

\subsubsection{Test's Validity}

The researcher examined the testing tool by viewing its primary image consisting of 25 questions about five skills of reflective thinking distributed on the stakeholders including; the faculty members in the Jordanian universities, supervisors and teachers. Based on the observations of stakeholders, questions were reformulated as they were not clear. Thus, 5 questions were deleted and the final image consisted of 20 questions. The appropriate time of answering questions is set according to the average time of answering questions by the first three and last three. The appropriate time was almost 40 minutes.

The examination of test tools depends on two ways; test and retest. It was applied on another survey sample, which consisted of 25 students. This group was retested after two weeks. The stability factor (Pearson correlation coefficient or the reliability factor) has been calculated and it was 0.91 . In the second test, the internal consistency factor was calculated using Kuder- Richardson 20, which was 0.93 . These two values confirm to the aim of the 
study.

\subsubsection{Scientific Concepts Test}

The test was set to examine the level of perception of the scientific concepts by primary third grade students of the two units Substance, Power, and Machines, from the science book. Results have been used to discover the effect of discrepancy and roundhouse strategies and compare it to the traditional way of acquiring the scientific concepts. The test consisted of 22 questions. Moreover, it was a multiple-choice testing with four choices among which one was correct.

\subsubsection{Validity of Scientific Concepts Test}

The validity of the test was examined by 16 stakeholders, who were specialized tutors in the curriculums and methods of teaching science, education administrators, and science teachers of primary third grade students. On the basis of suggestions, some questions were deleted, some were replaced, and some diagrams were clarified. The test consisted of 22 questions. It was applied on another survey sample after confirming the validity of the test. It consisted of 25 students from one of the primary third grade classes, chosen from Oxford school and belonged to the Amman directorate of education private province. The aim of the test was to set the appropriate time that is being taken to answer questions by the first three and last three respondents. Approximately, the appropriate time was 40 minutes. The test also helped in defining the clarity of the test. Some students questioned regarding some of the diagrams and choices which have been edited. Complexity and discrimination factors have also been defined; complexity factor less than $(0.22)$ were disqualified, also the ones with a complexity factor more than $(0.80)$. In addition, questions with a discrimination coefficient less than $(0.22)$ were also disqualified.

\subsubsection{Reliability of Scientific Concepts Test}

The examination of reliability depended on two ways; test and retest. It was applied on a different survey sample, consisting of 27 students. After two weeks, this sample was retested. The stability factor (Pearson correlation coefficient or the reliability factor) was calculated to be 0.91 . In the second test, the internal consistency factor was calculated using Kuder - Richardson 20, which was (0.88) confirming to the aim of the study.

\subsubsection{Educational Material}

The curriculum of primary third grade Science book contained two units (Matter, Power, and Machines) was used. The study plans were designed for two guides. Each plan contained a description for the discrepancy and roundhouse strategies including; guidelines, directions and various activities. The curriculum was organized according to strategies along with the content of the book and the learned lessons. The three groups were taught the same content to guarantee equity and no new information was added to the curriculum, taking into consideration the differences between the two strategies (discrepancy strategy and roundhouse strategy). After designing, the study plans were edited by a group of experts in the approaches and methods of teaching science.

\subsection{Statistical Analysis}

The study questions were answered, after applying the experimental method. In addition, the null hypotheses were tested using descriptive statistics (average, standard deviation). Moreover, the inferential statistics were tested using ANOVA to calculate the results of the three groups (two experimental groups and one control group) divided by the first dependent variable of the reflective thinking test. The ANOVA test was also used to calculate the results of the third group (two experimental groups and one control group) divided by the second dependent variable for the study, which is the scientific concepts acquisition.

\section{Results}

The impact of teaching strategy (roundhouse strategy, discrepancy strategy or traditional strategy) on the improvement of reflective thinking skills of primary third grade students has been examined. For this purpose, averages and standard deviations for the performance of the study groups were divided by the post reflective thinking test and post test results (Table 1). 
Table 1. Averages and standard deviations of samples divided by the post reflective thinking test and post test

\begin{tabular}{lllllll}
\hline Group & Number & Maxima & Pre-test & \multicolumn{3}{c}{ Post test } \\
\cline { 4 - 7 } & & & Average & Standard deviation & Average & Standard deviation \\
Traditional & 20 & & 9.35 & 3.53 & 13.55 & 2.80 \\
Roundhouse & 20 & \multirow{2}{*}{20} & 9.50 & 3.43 & 17.85 & 1.84 \\
Discrepancy & 22 & & 10.18 & 3.26 & 16.14 & 2.48 \\
\hline
\end{tabular}

According to table 1, the highest average was for the first experimental group which was taught using the roundhouse strategy and reached 17.85. The average of the second experimental group taught using the discrepancy strategy was 16.14 . Average for the control group was 13.55 , who were taught in the traditional way. The statistical variances between the study samples at the level $(\alpha \leq 0.05)$ were defined after applying ANOVA as shown in table 2 .

Table 2. Analysis of the variance between the averages of samples divided by the post reflective thinking test

\begin{tabular}{llllll}
\hline $\begin{array}{l}\text { Source } \\
\text { of variance }\end{array}$ & $\begin{array}{l}\text { Sum } \\
\text { of squares }\end{array}$ & $\begin{array}{l}\text { Degrees } \\
\text { of freedom }\end{array}$ & $\begin{array}{l}\text { Mean } \\
\text { of squares }\end{array}$ & Calculated F & Significance level \\
\hline Pre-test & 27.129 & 1 & 27.129 & 4.996 & 0.029 \\
Teaching strategy & 183.365 & 2 & 91.682 & 16.883 & 0.000 \\
Error & 314.962 & 58 & 5.43 & & \\
Total & 529.694 & 61 & & & \\
\hline
\end{tabular}

According to table 2, the F-value was 16.883 , the level significance was 0.000 at the level $\alpha \leq 0.05$. This indicated that there are statistical variances between the samples divided by the post reflective thinking test. This means rejecting the first null hypothesis stating that there are no statistical variances at the significance level $(\alpha=0.05)$ between the teaching strategies (roundhouse, discrepancy and traditional) in developing the reflective thinking skills of primary third grade students. However, table 3 has shown the modified averages.

Table 3 has shown that the highest average was for the experimental group, which was taught using the roundhouse strategy that reached 17.89. The average of the second experimental group taught using discrepancy was 16.04. While, the average of the control group taught using the traditional way was 13.62. Table 4 has illustrated the results of Scheffe test that has evaluated the variance between groups. The statistical variance between the experimental groups was taught using the roundhouse strategy and the one which was taught using the traditional way was 4.27. In addition, the statistical variance between the experimental group which was taught using the roundhouse strategy and the one which was taught using discrepancy was 1.85. Moreover, the statistical variance between the experimental group which was taught using discrepancy and the one which was taught using the traditional way was 2.42 .

Table 3. Averages and standard errors for the study groups divided by post reflective thinking test

\begin{tabular}{llll}
\hline Group & Number & Average & Standard error \\
\hline Traditional & 20 & 13.62 & 0.52 \\
Roundhouse & 20 & 17.89 & 0.52 \\
Discrepancy & 22 & 16.04 & 0.50 \\
\hline
\end{tabular}

Table 4. Results of Scheffe test for the variances between study samples divided by post reflective thinking test

\begin{tabular}{lllll}
\hline Group & & Roundhouse & Discrepancy & Traditional \\
\cline { 3 - 5 } & Average & 17.89 & 16.04 & 13.62 \\
Roundhouse & 17.89 & - & $* 1.85$ & $* 4.27$ \\
Discrepancy & 16.04 & & - & $* 2.42$ \\
Traditional & 13.62 & & & - \\
\hline
\end{tabular}

Table 5 has shown the highest average for the first experimental group, which was taught using the roundhouse 
strategy and it reached 19.85. The average of the second experimental group taught using contradiction was 18.09 . While, the average of the control group that was taught using the traditional way was 15.40. The statistical variances between the study samples at the level $(\alpha \leq 0.05)$ were defined after applying ANOVA.

Table 5. Averages and standard deviations for the performance of samples divided by post scientific concepts test and pre-grades

\begin{tabular}{lllllll}
\hline & & \multicolumn{3}{c}{ Pre-test } & \multicolumn{3}{c}{ Post test } \\
\cline { 4 - 7 } Group & Number & Maxima & Average & Standard deviation & Average & Standard deviation \\
Traditional & 20 & & 8.70 & 3.42 & 15.40 & 2.68 \\
Roundhouse & 20 & & 9.25 & 3.55 & 19.85 & 1.53 \\
Discrepancy & 22 & 20 & 9.82 & 3.81 & 18.09 & 2.39 \\
\hline
\end{tabular}

According to table 6, F-value was 19.144 and the level significance was 0.000 at the level $(\alpha \leq 0.05)$, which indicated that there are statistical variances between the study samples divided by the post scientific concepts test. This means the first null hypothesis which stating that there are no statistical variances at the significance level ( $\alpha$ $=0.05$ ) between the teaching strategies (roundhouse, discrepancy and traditional) in scientific concepts acquisition by primary third grade students have been rejected.

Table 6. Analysis of ANCOVA for the variance between samples divided by post scientific concepts test

\begin{tabular}{llllll}
\hline $\begin{array}{l}\text { Source } \\
\text { of variance }\end{array}$ & $\begin{array}{l}\text { Sum } \\
\text { of squares }\end{array}$ & $\begin{array}{l}\text { Degrees } \\
\text { of freedom }\end{array}$ & $\begin{array}{l}\text { Mean } \\
\text { of squares }\end{array}$ & Calculated F & Significance level \\
\hline Pre-test & 6.118 & 1 & 6.118 & 1.203 & 0.277 \\
Teaching strategy & 194.775 & 2 & 97.387 & 19.144 & 0.000 \\
Error & 295.05 & 58 & 5.087 & & \\
Total & 502.274 & 61 & & & \\
\hline
\end{tabular}

Table 7 has shown the highest average for the experimental group, which was taught using roundhouse strategy reaching value of 19.85. The average of the second experimental group that was taught using discrepancy was 18.04. While, the average of the control group, which was taught using the traditional was 15.45 . The variance between groups was calculated through Scheffe test and the results have been depicted in table 7 .

Table 7. Averages and standard errors of samples divided by post scientific concepts test

\begin{tabular}{llll}
\hline Group & Number & Average & Standard error \\
\hline Traditional & 20 & 15.45 & 0.51 \\
Roundhouse & 20 & 19.85 & 0.50 \\
Discrepancy & 22 & 18.04 & 0.48 \\
\hline
\end{tabular}

\section{Discussion}

Roundhouse strategy helps students in defining relationships between concepts and link them to pictures and diagrams in an organized format. Therefore, students will be able to comprehend abstract concepts easily, retain information, and store it in their knowledge, which makes the learning meaningful. Moreover, this strategy has summarized a great amount of knowledge. Finally, roundhouse strategy can develop brain hemispheres, as for the right part it deals with pictures, coloring, and formulating mental images for concepts (the creative part). While, in left part, it deals with concepts and information sequentially and consecutively. It also deals with expressing and explaining the roundhouse diagram verbally by students that improves retaining and comprehending the scientific concepts.

This result corresponds with the results of previous studies which has approved the excellence of roundhouse 
strategy in acquiring the scientific concepts and developing the reflective thinking skills (Westbrook \& Rogers, 1991; Ward \& Wandersee, 2002a; 2002b). Roundhouse strategy is also based on the constructivist theory; it's one of the metacognitive strategies suggested by Wandersee et al. (1994). The roundhouse is a diagram that is similar to the two-wheeler dimensions, the center of the conceptual turntable has a line through which it is optional. Each sector contains a "chunk" of information, letters or words which are; from or in or and. As for the axis; it's a circle that surround the turntable. It resembles the outer parts for the wheel consisting of seven sectors which are called "chunks" and these sectors are linked to the center. They are used to demonstrate the major scientific concept (Ward \& Wandersee, 2002a; Ambo Sa'eedi \& Al-Bloushi, 2011).

Ward \& Lee (2006) discovered the efficiency of the roundhouse strategy in helping 8th grade students, Louisiana, United States, to understand chemistry. To achieve the aim of the study, an achievement test for the elements of the periodic table was applied on the study sample. According to study results, students who were taught using the roundhouse strategy have achieved high degrees, unlike those who were taught using the traditional way. The strategy had exceptional results and it flexibly helped two weak students to improve their level by stimulating mental pictures. Moreover, using this strategy has made a clear and a significant impact. Orak et al. (2010) studied the impact of using roundhouse strategy to learn the power and motion unite by primary $7^{\text {th }}$ grade students in one of the Turkish schools. The study used quasi experiment strategy by recruiting 372 students chosen randomly from Van province, Turkey. The sample was divided into two groups; the experimental group consisted of 183 students, who were taught using the roundhouse strategy; while, the control group was taught using the traditional way. The study used an achievement test, a computerized program, and a questionnaire to know the students' opinions in the used strategy. Results have shown statistical differences in the averages of the achievement test. The results were in favor of the experimental group, which indicated that the roundhouse strategy was effective.

\section{Conclusion}

Roundhouse strategy and discrepancy strategy has clearly improved perception of scientific concepts and reflective thinking by primary third grade students, as they connect new knowledge with prior knowledge taking hierarchy into consideration. As a result, knowledge is likely to be preserved in long-term memory. This would help in achieving meaningful learning that enable students to reach high levels of thinking. Moreover, it helped students to divide the main concept into chunks of information and link them to pictures and diagrams. They will be able to retain information and remember it easily, as well as, correct and simplify the concepts. Furthermore, this strategy combined two approaches of science; the theoretical one and practical one. This enable the students to use high levels of reflective thinking leading to improvement in the practical work that is the basic of scientific thinking skills. The study results are limited as they are confined to a sample of primary third grade students from Al-Hijaz School belonging to the education directorate in Amman private district-Amman of the school year 2016/2017. The generality of the study results can be determined by reflective thinking and scientific concepts tests, which are prepared by the researcher, in addition to the indicators of validity and reliability.

Based on the positive results of using discrepancy strategy and roundhouse strategy in the acquisition of scientific concepts and reflective thinking by primary third grade students, the study has indicated educational situations, which require using the roundhouse strategy and reflective thinking strategy taking the cognitive levels into consideration. The two guides of science teachers can be used as a model for preparing and teaching using the roundhouse strategy and discrepancy strategy. Future studies need to study about the impact of using roundhouse strategy on other stages and discusses other implications, for instance; developing logical thinking, inferential thinking, analytical thinking, or the way of thinking.

\section{Acknowledgement}

The author is very thankful to all the associated personnel in any reference that contributed in/for the purpose of this research.

\section{Competing Interest}

The author declares no competing interest.

\section{Funding}

This research is not funded by any resource.

\section{References}

Al Shaar, E. M., Khattab, S. A., Alkaied, R. N., \& Manna, A. Q. (2015). The effect of top management support on innovation: The mediating role of synergy between organizational structure and information technology. International Review of Management and Business Research, 4(2), 499. 
Al-Harahsheh, K. (2012). The Effect of Analogy Strategy in Science Teaching on Scientific Concepts acquisition and Basic science Processes Skills. Damascus University Journal, 28(2), 411-451.

Al-Mazrou, H. (2005). The Roundhouse Strategy: The Impact on the Development of Metacognitive Skills and Science Averages of Different Stages of High School Students. Gulf Message Magazine, 36, 13-67.

Al-Qatrawi, A. A. (2010). The Impact of Using Strategy of similarities on developing Scientific Processes and Reflective Thinking Skills of Primary Eighth Grade Students (unpublished master letter, The Islamic College, Gaza).

Al-Saleem, M. (2004). The Efficiency of Constructivism on the Constructivist Teaching Skills of Science teachers and its Impact on Correcting the Alternative Perceptions of the Chemical and Geochemical Changes of Middle stage students in Riyadh. King Saud Magazine for Educational Science and Islamic Studies, 2(16), 687-766.

Ambo Sa'eedi, A., \& Al-Bloushi, S. (2011). Strategies of Teaching Science, Concepts and Practical work, Amman, Al-Masirah House for Publishing and Distributing.

Barbosa, L. H., Talero, P. H., Rodríguez, J. O. O., \& Hernández, L. (2011). The discrepant experiments as a captivating scenario with educational social role. Latin-American Journal of Physics Education, 5(1), 21.

Fisher, K., Wandersee, J., \& Moody, D. (2000). Mapping Biology Knowledge. Kluwer Academic Publishers.

Friedl, A. (1995). Teaching Science to Children (3rd ed.). New York. Mc GawHill, Inc.

Kuhn, D., \& Dean, D. (2004). Metacognition: A bridge between Cognitive Psychological and Educational Practice. Theory in Practice, 43(4), 268-273. https://doi.org/10.1353/tip.2004.0047

Kwon, J., Lee, Y., \& Beeth, M. E. (2000). The Effects of Cognitive Conflict on Students' Conceptual Change in Physics.

Lyons, N. (2010). Handbook of reflection and reflective inquiry: Mapping a Way of Knowing for professional reflective inquiry, U.S.A.

Martin, R. E., Sexton, C. M., Franklin, T. J., Gerlovich, J. A., \& McElroy, D. (2009). Teaching science for all children: An inquiry approach, New York, NY: Pearson.

Orak, S., Erms, F., Yesilyurt, M., \& Keser, O. (2010). The Effect of Roundhouse Diagrams on the Success in Learning. Electronic Journal of Social Science, 9(31), 118-139.

Phan, H. P. (2008). Predicting change in epistemological beliefs, reflective thinking and learning styles: A longitudinal study. British journal of educational psychology, 78(1), 75-93. https://doi.org/10.1348/000709907x204354

Redmond, B. (2017). Reflection in action: Developing reflective practice in health and social services, Routledge.

Reed, M., \& Canning, N. (2010). Reflective Practice in the Early Years, London: Sage, 2010.

Ross, A., \& Wilson, V. (2012). The Effects of Representations, Constructivist Approaches and Engagement on Middle School Students' Algebraic Procedure and Conceptual Understanding. School Science and Mathematics, 112(2), 117-128. https://doi.org/10.1111/j.1949-8594.2011.00125.x

Wandersee, J. H., Mintzes, J. J., \& Novak, J. D. (1994). Research on alternative conceptions in science. Handbook of research on science teaching and learning, 177, 210.

Ward, R. E., \& Lee, W. D. (2006). Understanding the periodic table of elements via iconic mapping and sequential diagramming. The roundhouse strategy, Science Activities: Classroom Projects and Curriculum Ideas, 42(4), 11-19. https://doi.org/10.3200/sats.42.4.11-19

Ward, R. E., \& Wandersee, J. H. (2002a). Students' perceptions of Roundhouse diagramming: a middle-school

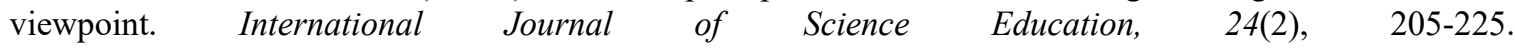
https://doi.org/10.1080/09500690110074008

Ward, R. E., \& Wandersee, J. H. (2002b). Struggling to understand abstract science topics: A Roundhouse diagrambased study. International Journal of Science Education, 24(6), 575-591. https://doi.org/10.1080/09500690110074017

Westbrook, S. L., \& Rogers, L. N. (1991). An Analysis of the Relationship between Student-Invented Hypotheses and the Development of Reflective Thinking Strategies. 


\section{Copyrights}

Copyright for this article is retained by the author(s), with first publication rights granted to the journal.

This is an open-access article distributed under the terms and conditions of the Creative Commons Attribution license (http://creativecommons.org/licenses/by/4.0/). 